\title{
When is a drought a drought?
}

Michael H. Glantz and Richard W. Katz, of the Environmental and Societal Impacts Group at the National Center for Atmospheric Research, Boulder, Colorado, draw on the case of the Sahel to comment on the use of the term 'drought' for arid regions

THE word 'drought' has various interpretations: decisionmakers, political and otherwise, underestimate its likelihood in and around regions where interannual rainfall variability is relatively high. In such arid and semiarid areas, recurrent droughts are in fact a part of climate and not apart from it, and therefore should not be viewed as unexpected events.

The West African Sahel, one such area, has recently been affected by its third major extended drought this century. Many observers have suggested that the drought, which began in various parts of the region in 1968, ended with a return to normal or near normal rainfall. Some interpreted the relatively good rains in 1974 as indicative of a resumption of 'normal' rainfall. Similar statements have been common in the growing volume of drought literature. However, they can mislead because they imply that a return to normal rainfall, that is, rainfall seen as an 'average', is associated with a return to acceptable if not favourable meteorological, agricultural and social conditions for the region. The validity of such an assumption is questionable.

What is perceived as 'normal' rainfall is an important, yet often overlooked, aspect of what is meant by 'drought' in arid and semiarid regions. People react to their perceptions whether or not those perceptions are based on reality, and the consequences of those reactions are real. It is misleading to view 'normal' as a 'normative quantity' with the implication that a departure is 'abnormal': a 'normal' has no predictive value. The literature concerned with droughts in arid and semiarid regions is replete with references to particularly dry years as being abnormal or anomalous. Yet, because perceptions about what con- stitutes a drought vary, there is no widely accepted definition of drought. The scores of existing definitions, however, are either meteorological or agricultural. A meteorological drought could arbitrarily be defined as that period when the amount of precipitation is less than some designated percentage of the long-term mean, whereas an agricultural drought could be defined in terms of the timing of the rainfall which is crucial to crop development.

In reality, the subjective distinction between a dry spell and a genuine drought is a difficult one to make. Most American farmers do not call a dry spell a drought until the moisture shortage has seriously affected the established economy of the region. These observations apply equally well to similar situations in arid areas. It has been suggested that there should be at least two components to a definition of drought: a physical one and a social one. A mix of dry spell and meteorological drought occurred at various times and various places in the Sahel between 1968 and 1974, but their impacts were worsened by the pressure of populations, both human and livestock.

A major problem associated with the perception of drought is the constantly changing nature of those perceptions. Recent weather tends to influence perceptions more heavily than earlier weather and wet spells more heavily than dry ones. On this basis it has been suggested that the inhabitants of the Sahel have adopted practices during the abnormally wet years which end in disaster during the dry years. After a period of abnormally high rainfall in the Sahel which ended about 1965, the inhabitants considered a return to average conditions for rainfall to be a 'drought'.

What, then, does a return to average rainfall conditions in arid and semiarid regions mean? Of what importance is it when a return to 'normal' or near normal rainfall is perceived to be a return to drought-like conditions? Take the case of the Sahel, a climatic zone in sub-Saharan Africa which receives $200-600 \mathrm{~mm}$ of annual mean rainfall. It is bordered on the north by subdesert $(100-200 \mathrm{~mm})$ and to the south by the Sudan $(600-900 \mathrm{~mm})$. Rain falls during

August precipitation $1941-75$
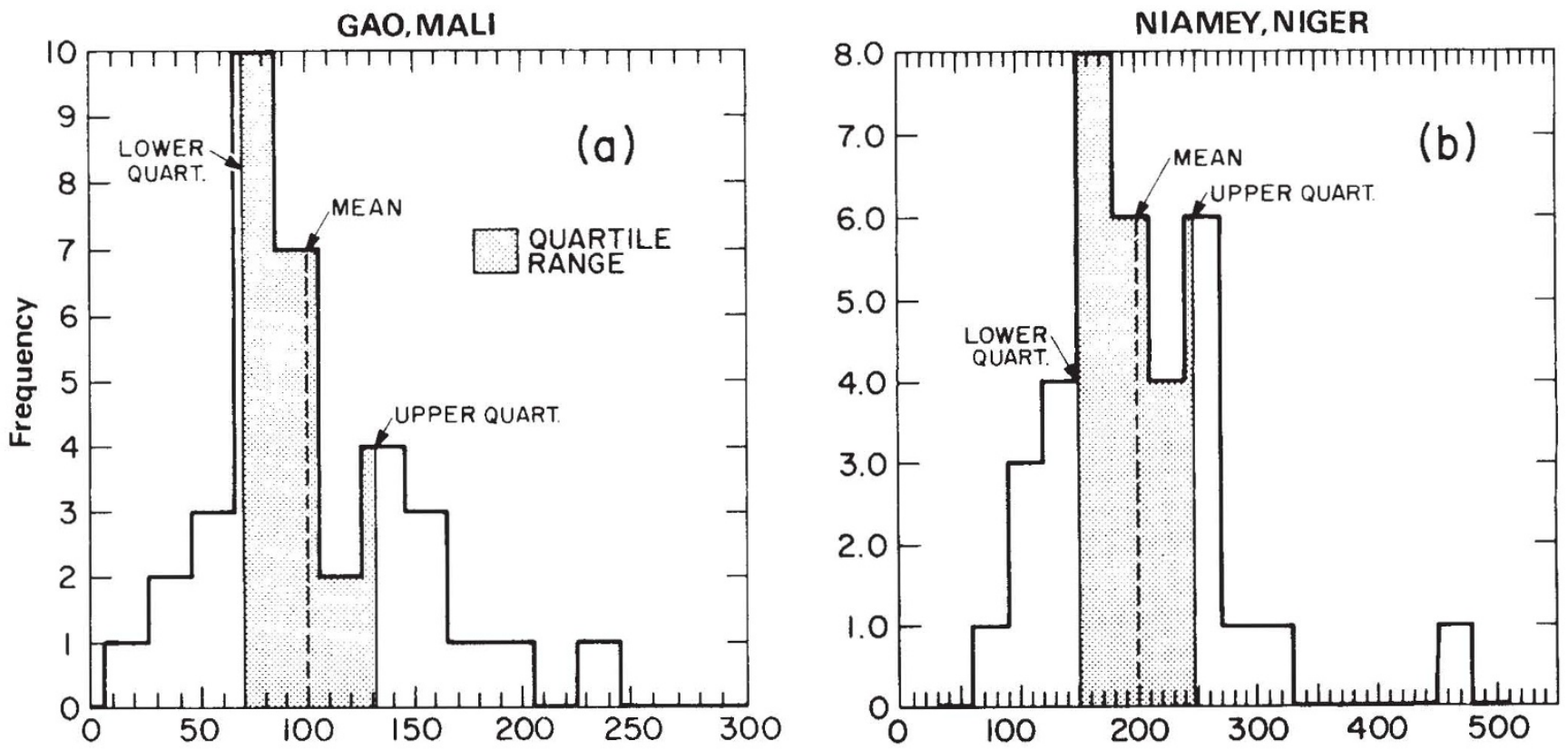

Precipitation $(\mathrm{mm})$ 
convective thunderstorms over a four-month period beginning in June. It is this highly variable rainfall on which the region's inhabitants depend for the cultivation of their crops and the maintenance of their herds.

August rainfall data are significant in that August is nearly always the wettest month and it marks the midpoint of the rainy season. We have looked at rainfall statistics for arid zones by taking the August rainfall records for two cities within the Sahel-Gao, Mali $\left(16.3^{\circ} \mathrm{N}, 0.1^{\circ} \mathrm{W}\right)$ and Niamey, Niger $\left(13.5^{\circ} \mathrm{N}, 2.1^{\circ} \mathrm{E}\right)$-and have found that Sahelian rainfall shows a relatively high degree of variability. Many analyses, however, have not included a plot of the actual data but have relied on the use of descriptive statistical terms such as the mean or the running mean. Such terms fail to reveal magnitude and variability which are major factors in understanding the nature of rainfall in arid and semiarid lands.

Histograms derived from the data for Gao and Niamey show a 'positively skewed' frequency distribution, small amounts of rainfall occurring more frequently than relatively large amounts. This type of skewness is characteristic of the rainfall distribution not only in the Sahel but, more generally, in arid and semiarid regions. In particular, the degree of skewness is greater the drier the climate.

The mean, which is commonly taken to represent 'normal' rainfall, is extremely sensitive to skewness because it is inflated by the relatively few cases of large values: more than half of the observations fall below the mean. As a result, rainfall observations close to the mean value do not occur often in the Sahel, showing that, at least in some sense, the mean is too large and not at all indicative of how much rain commonly falls.

The median marks the amount of precipitation which is exceeded one half of the time, while the mode represents the amount of precipitation which is most likely to occur. Since neither of these measures is greatly affected by skewness, their interpretations remain clear. In particular, for a positively skewed distribution they are usually smaller in value than the mean.

For the Sahel, therefore, the mean, in reality, is above 'normal', while the median and the mode can still be interpreted, in the sense just discussed, as 'normal'. Hence although most analyses of Sahelian rainfall assume that the mean is an appropriate measure of central tendency, either the median or the mode may, depending on the circumstances, be preferable and no single number can adequately represent the distribution of Sahelian rainfall, given the large deviations from each of the measures of central tendency. 'Normal' rainfall, however, can be better characterised by the interquartile range than by any of the standard measures of central tendency.

Measuring the variability of Sahelian rainfall is further complicated by the possibility of trends or cycles or other evidence of climatic change in the data: there is strong disagreement among researchers over whether significant trends or cycles do exist. Although they might well exist, there may have been an inordinate degree of effort devoted to hidden periodicity' research and this has tended to obscure the most important aspect of Sahelian rainfall-its extreme variability. In fact, even if trends or cycles do exist, it is almost universally agreed that they would be of limited predictive value.

Aside from the absolute amounts of rainfall, as measured over varying lengths of time, other factors such as spatial distribution, timing, wind velocity and evapotranspiration could have an important impact on the social value to the inhabitants of the rain that does fall. If rainfall information, which represents only one climatic variable, is not viewed within its total environmental context, it can be extremely misleading. Where long-range development planning is concerned, such an oversight can be disastrous. Such has often been the case in fragile ecosystems like those in

\section{Sorry, for copyright reasons some images on this page may not be available online}

arid and semiarid regions.

Desertification-the creation of desert-like conditions where none had existed before-is the result of either the vagaries of weather and climate or the mismanagement of the land or, as in most cases, some combination of both. Such ecological deterioration in the Sahel has been linked in several ways to the increased sizes of livestock herds. During extremely favourable periods of rainfall, as was the fifteen-year period preceding 1968 , the pastoralists moved into the marginal regions in the north with relatively large herds. However, with the onset of a series of dry years beginning at the end of the rainy season in 1967, the pastoral populations found themselves overtaxing very marginal range-lands with the result that the nomads viewed themselves as victims of a natural disaster.

Deterioration and ultimately desertification in the Sahel and in similar ecosystems could be combated if an ecologically realistic carrying capacity for the rangelands was determined. Although there appears to be widespread acceptance that such a determination would be significant, there has been little agreement to date on how to make operational the notion of carrying capacity (defined as the amount of grazing stock that the pasture can support without deterioration of either the pasture or the stock). Should the carrying capacity be geared to the best, the average, or the poorest years? Which combination of statistical measures would be most meaningful for the planning of long-term development of rangelands? On which variables should such an assessment be based-vegetation, rainfall, soil, ground and surface water, or managerial capabilities? Such inconclusiveness within the scientific community, while understandable, creates confusion for the decision-makers, who often decide either to take no action or who decide that all scientific suggestions are of equal weight and, therefore, indiscriminately choose any one of those suggested. Given the downward spiral of land deterioration it becomes essential that an ecologically acceptable carrying capacity be established and enforced.

The mistaken idea that drought in the Sahel is an unexpected event has often been used to excuse the fact that long-range planning has failed to take rainfall variability into account. People blame the climate for agricultural failures in semiarid regions making it a scapegoat for faulty population and agricultural policies. It will therefore be crucial that decision-makers know what statistical and quasi-statistical measures actually mean: no single number can adequately describe the climate regime of an arid or semiarid region. Decision-makers must supplement such terms as the 'mean' with more informative statistical measures to characterise adequately the variability of the climate. An understanding of this high degree of variability will serve to remove one of the major obstacles to resolving the perennial problems of the Sahel and of other arid or semiarid regions, 